\title{
FENÓMENOS DE LO EFÍMERO. OTRAS ARQUITECTURAS EFÍMERAS EN COLOMBIA
}

Fenômenos do efémico.

Outras Arquiteturas Eficazes na Colômbia

Phenomena of the ephemeral.

Other ephemeral architecture in Colombia.

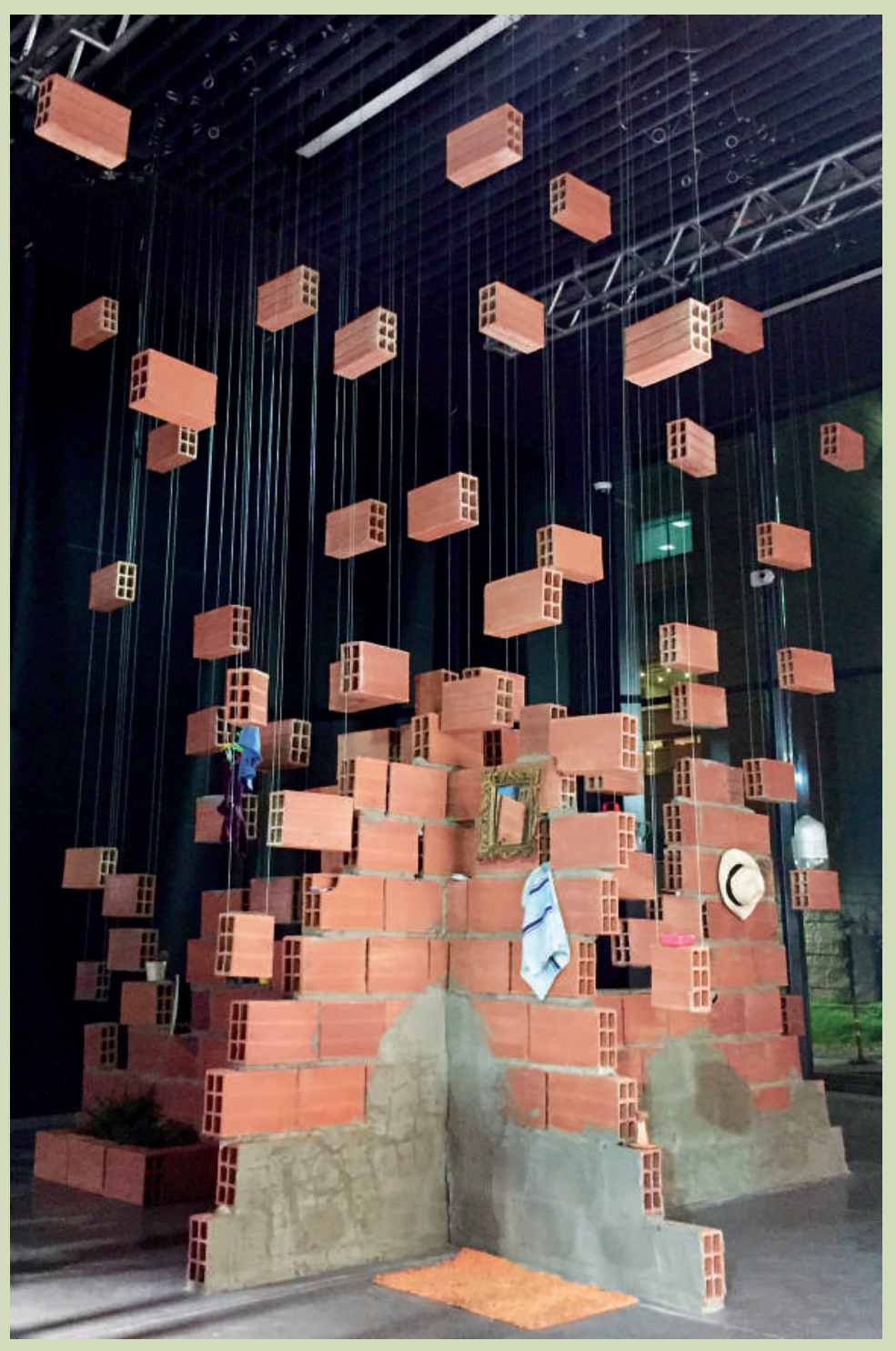

William García Ramírez.

Profesor de la Facultad de Arquitectura y Diseño. Pontificia Universidad Javeriana de Colombia. Bogotá, Colombia.

william.garcia@javeriana.edu.co

https://orcid.org/0000-0002-0434-0358

Artículo basado en los resultados de la investigación "Análisis de las memorias descriptivas, Actas de juzgamiento y Planimetrías en las Bienales Colombianas de Arquitectura: Arquitectura de la Vivienda (1990-2016)". ID Proyecto 8236. Investigador:William García Ramírez. Institución patrocinadora: Pontificia Universidad Javeriana.

Casas de Arena.

Instalación artística de Juanita Orbegozo. Fuente:

William García R.

(2019) 


\title{
RESUMEN
}

Este artículo tiene como objetivo analizar el fenómeno de la arquitectura efímera en Colombia, desde un ángulo donde lo efímero se deriva de las condiciones de durabilidad de las obras como resultado de factores de calidad y/o del abandono de estas arquitecturas. Por lo tanto, la investigación tuvo como punto de partida metodológico una revisión historiográfica contrastada, que incluyó visitas a arquitecturas en las que se ha visto comprometida su estabilidad y por ende su durabilidad, como factor que ha determinado su condición efímera, toda vez que se trata de arquitecturas que han desaparecido de manera súbita, o que una vez abandonadas, se encuentran en un lento proceso de desaparición. El análisis de estas arquitecturas permitió detectar dos fenómenos principales de lo efímero en Colombia, tomando como punto de partida la velocidad y la intencionalidad en la desaparición de estas arquitecturas, (Utopías efímeras: lugares ideales para el hábitat, involuntariamente efímeros) y (Distopías efímeras: lugares imposibles para el hábitat, deliberadamente efímeros) Estas dos categorías de aproximación delimitan un panorama alternativo de la arquitectura efímera en Colombia, que redimensiona y amplía la visión tradicional de este tipo de arquitectura.

Palabras clave: Arquitectura efímera, calidad, crítica de la arquitectura, historia de la arquitectura, Colombia.

\section{RESUMO}

Este artigo tem como objetivo principal, analisar o fenômeno da arquitetura efêmera na Colômbia a partir De um ângulo onde o efêmero deriva das condições de durabilidade das obras como resultado de fatores de qualidade e/ou do abandono destas arquiteturas. Por conseguinte, a pesquisa teve como ponto de partida metodológico uma revisão historiográfica comprovada, que incluiu visitas a arquiteturas em que a sua estabilidade e, portanto, a sua durabilidade foram comprometidas como factor que determinou a sua condição efémera, já que são arquiteturas que desapareceram de repente, ou uma vez abandonadas, estão num lento processo de desaparecimento. A análise destas arquiteturas nos permitiu detectar dois fenômenos principais do efêmero na Colômbia, tomando como ponto de partida a velocidade e intencionalidade no desaparecimento destas arquiteturas, (Utopias efémeras: lugares ideais para o habitat, não intencionalmente efémeras) y (Distopias efémeras: lugares impossíveis para o habitat, deliberadamente efémeras). Estas duas categorias de abordagem delimitam um panorama alternativo de arquitectura efémera na Colômbia, que redimensiona e expande a visão tradicional deste tipo de arquitectura.

Palavras chave: Arquitetura efêmera, qualidade, crítica da arquitetura, história da arquitetura, Colombia

\begin{abstract}
The main purpose of this paper is analyzing the phenomenon of ephemeral architecture in Colombia from an angle where the ephemeral is derived from the durability of the works, as a result of quality factors and/or the abandonment of these architectures. Therefore, the methodological starting point of the research was a contrasted historiographic review, including visits to architectures whose stability and, hence, durability, have been questioned as a factor that has determined their ephemeral condition, since these architectures have disappeared suddenly or, once abandoned, are in slowly disappearing. The analysis of these architectures allowed detecting two main ephemeral phenomena in Colombia, taking as a starting point the speed and the intentionality in the disappearance of these architectures, (Ephemeral utopias: ideal places for habitat, unintentionally ephemeral) and (Ephemeral dystopias: impossible places for habitat, deliberately ephemeral). These two categories of approximation define an alternative panorama of ephemeral architecture in Colombia, which resizes and expands the traditional view of this type of architecture.
\end{abstract}

Keywords: Ephemeral arquitechture, quality, critica lof arquitectura, history of arquitectura, Colombia. 


\section{INTRODUCCIÓN}

Allí donde había obras, solo quedan experiencias

Yves Michaud
Esta es una de las principales conclusiones a las que llega Yves Michaud en su libro El arte en estado gaseoso, un ensayo que señala la paradoja de habitar en un mundo donde los objetos materiales cobran inusitado valor, en tanto la obra de arte tiende a diluirse en una suerte de prácticas y performances, de los que tan solo queda una experiencia pasajera. A través de este ensayo es posible reconocer no solo una narrativa de los valores del mundo contemporáneo de las artes, sino una tendencia más amplia, donde lo efímero permea, desde la producción de objetos de obsolescencia programada, hasta la generación de aplicaciones tecnológicas (apps) que ofrecen nuevas y rápidas experiencias de consumo en la ciudad, una tendencia de la que no puede abstraerse ninguna disciplina, incluida la arquitectura. Empero, no se trata aquí de hacer un llamado a la arquitectura de obsolescencia programada, esto es, la arquitectura que a pesar de estar en buenas condiciones ha dejado de usarse, sino por el contrario, a la arquitectura que ha dejado de usarse por causa de la urgencia de los tiempos. Parafraseando a Marta Traba: una arquitectura producida de manera rápida, tan rápida que ha llevado a algunos arquitectos e ingenieros a buscar subterfugios para llegar, como la liebre, antes que la tortuga a la meta, y que ha generado un fenómeno en el que la arquitectura desaparece y se convierte en efímera, por ignorar algo que los grandes arquitectos saben desde siempre: que los subterfugios son inútiles en arquitectura, que el desarrollo de una arquitectura de calidad es una de las pocas cosas que en un mundo acelerado no puede precipitarse artificialmente. Así, la investigación se orientó a indagar en este fenómeno, que se ha venido agudizando en Colombia durante las últimas décadas.

En la ciudad de Cartagena el proyecto Torre de la Escollera, un edificio de apartamentos previsto para alcanzar los 50 pisos de altura, tuvo que ser demolido en 2008 sin haber finalizado su construcción, pues la estructura del edificio sufrió una torsión en medio de un vendaval, causada por la carencia de riostras o diagonales en la estructura metálica que soportaría el edificio. Ocho años después, en la misma ciudad, se desplomó el edificio Portal de Blas de Lezo II, un proyecto de vivienda, de 7 pisos casi terminado, cuyo repentino colapso obedeció también a defectos constructivos (Madariaga, 2019). En la segunda década del presente siglo las cosas no han ido mejor, el puente Chirajara, una infraestructura de 446 metros de longitud, ubicada entre las ciudades de Bogotá y Villavicencio, concebida como el puente más largo del país construido con estructura de tensores, colapsó en uno de sus extremos, el 15 de enero de 2018, a menos de dos meses de su finalización, lo que llevó a su demolición total 6 meses después [Figura I]. Ese mismo año, uno de los proyectos de infraestructura más grandes en la historia del país, la hidroeléctrica de Hidroituango, estuvo a punto de colapsar debido a fallos constructivos y de gestión, por lo que su inauguración - prevista para 2018- tuvo que ser pospuesta al menos por 4 años más como consecuencia de las soluciones de emergencia que se tomaron con el fin de evitar la rotura de la estructura principal. 


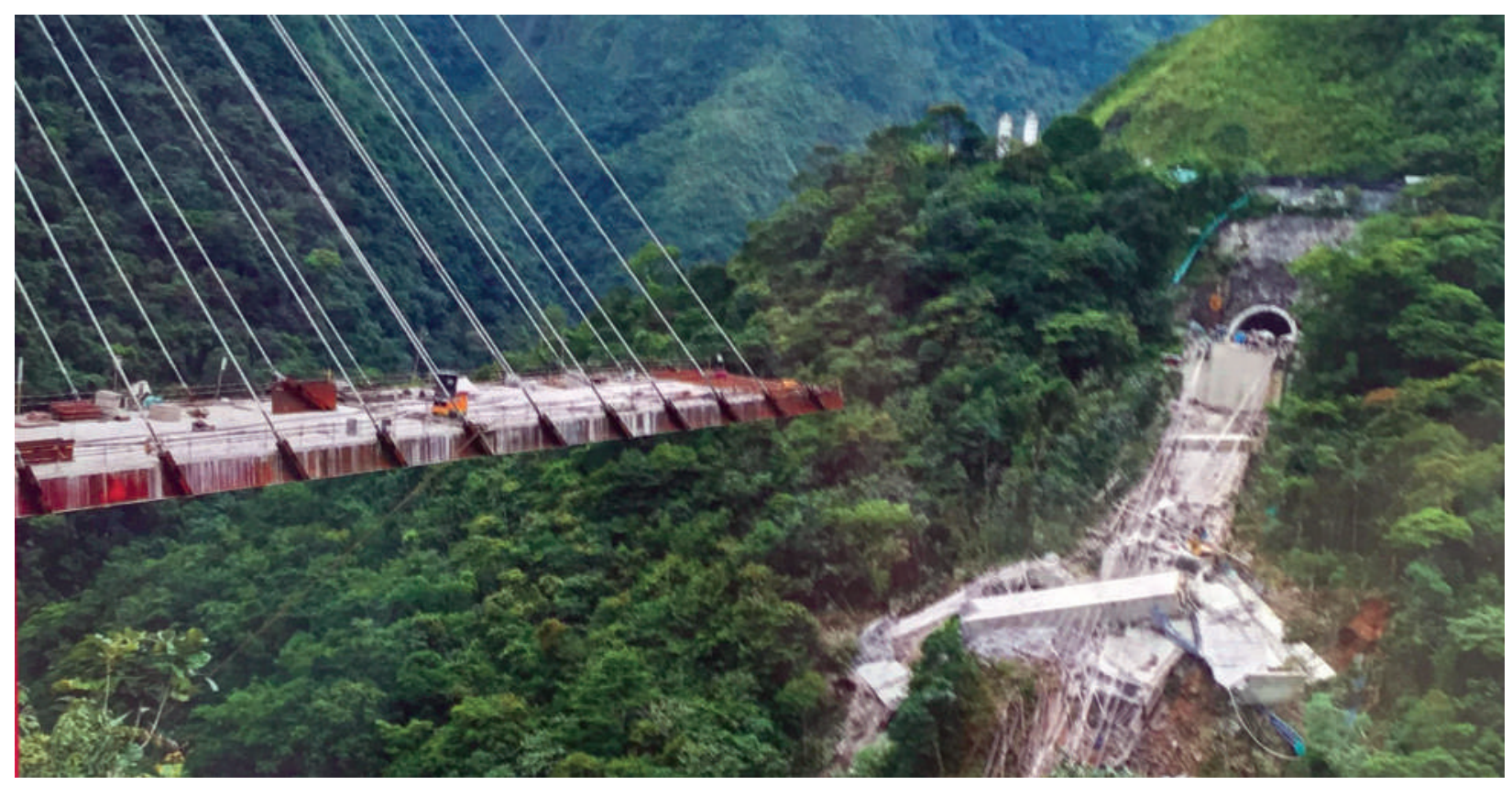

Figura 1

Puente Chirajara.

Fuente: Guillermo

Torres (2018).
Así, vemos cómo la otrora condición - sine qua non- del firmitas en arquitectura, ha empezado a verse comprometida en Colombia, lo que ha configurado un panorama inusitado de la arquitectura efímera que redefine la noción tradicional de lo que se considera efímero en arquitectura. Entre 2018 y 2019 se han demolido 6 infraestructuras de reciente edificación, y a la fecha se mantienen numerosas infraestructuras públicas sin finalizar, algunas desde hace más de 30 años; la decisión de la multinacional portuguesa Mota Egil, el pasado mes de septiembre, de no terminar la construcción de aproximadamente 246 colegios en el país dejándolos en el limbo de la ruina no hace más que subrayar esta tendencia.

Empero, esta condición suspensiva en arquitectura no es un fenómeno exclusivamente local ni reciente: La inconclusa Ciudad Universitaria de Tucumán es muestra fehaciente del lento estado de desaparición, por causa del abandono del que sería uno de los centros universitarios más importantes de Argentina (Nicolini 2019). Hasta el día de hoy, las enormes estructuras inacabadas desde 1952, representan cómo el fenómeno de lo efímero en arquitectura no tiene que ver solamente con la desaparición de la arquitectura, sino con el olvido de que alguna vez estas existieron.

En otras latitudes, la tendencia a convertir en efímera, arquitectura que no ha sido prevista como tal, se produce por la incapacidad del hombre de anticipar situaciones que parecían previsibles. Desde la Torre de Pisa hasta el reciente colapso del viaducto Polcevera en Genova - Italia, evidencian esta realidad. Sin embargo, el caso del aeropuerto 


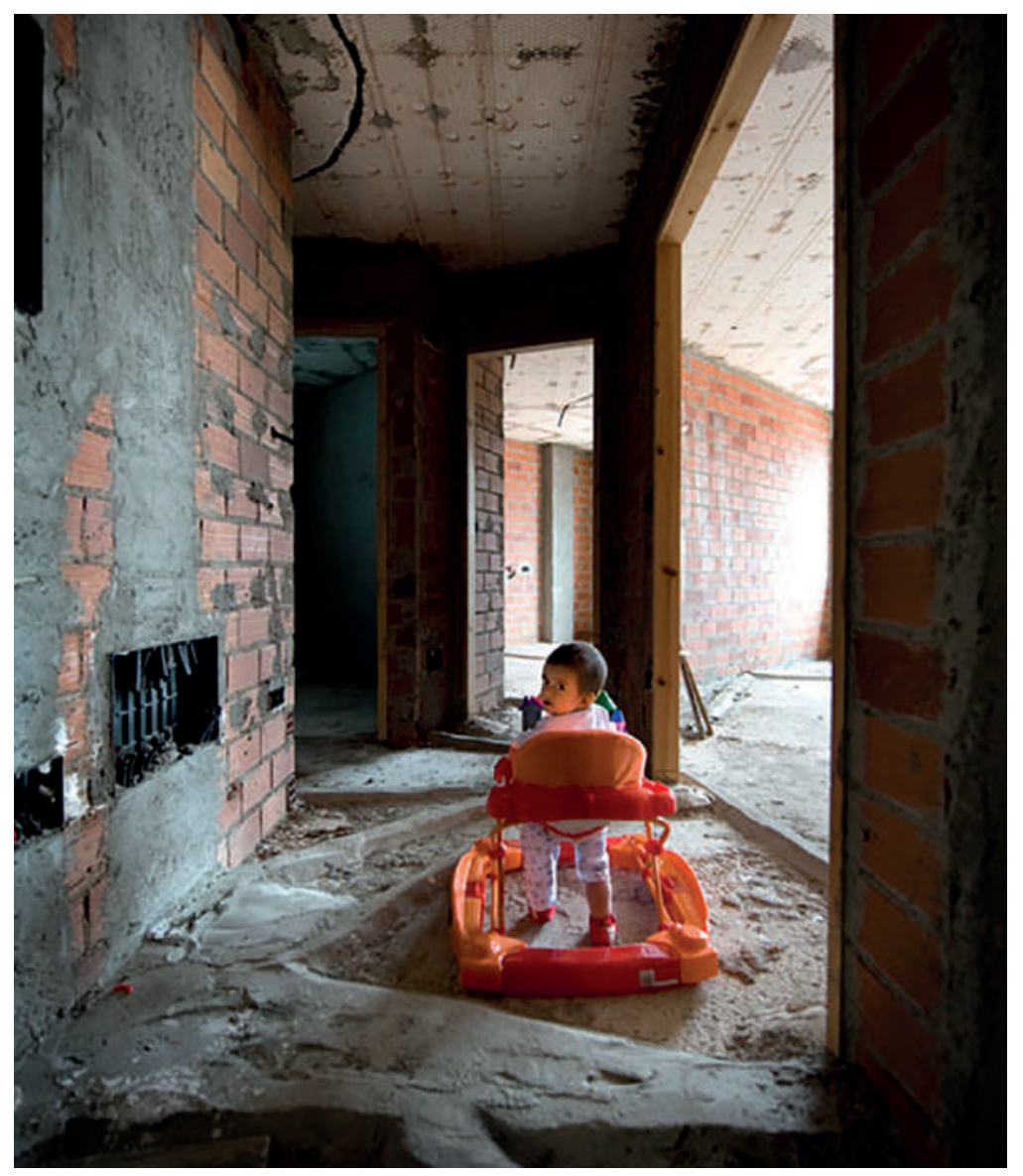

Figura 2

Unfinished - Miradas: Pabellón de España $X V$ Bienal de

Arquitectura de

Venecia (2016). León de Oro.

de Kansai en Japón representa una de las más costosas batallas por evitar la desaparición de una arquitectura desde que se descubrió que la isla artificial sobre la que fue construida se hundía mucho más rápido de lo previsto (Al-Badri, 2003). Esta situación ha llevado a implementar, desde su inauguración, diversas reparaciones en el edificio, las cuales, sin embargo, no evitaron que las pistas del aeropuerto más costoso del mundo quedaran bajo el agua en 20 I 8, a la llegada del tifón Jebi, situación que sigue cuestionando la viabilidad estructural y financiera de esta infraestructura.

España, país otrora de construcciones y arquitecturas faraónicas, se vio en la repentina obligación de aplazar indefinidamente la edificación de múltiples obras públicas y privadas por causa de la crisis económica de 2007, obras inacabadas a lo largo de todo el país que, con el tiempo, empezaron a deteriorarse por causa del abandono y del vandalismo, obras que sin proponérselo entraron en un lento proceso de ruina y desaparición [Figura 2]. Este fue el contexto que dio lugar al tema del Pabellón de España, presentado y premiado con el León de Oro en la Bienal de Arquitectura de Venecia de 2016: Unfinished, una revisión de la arquitectura abandonada, que entrada en ruina, busca ser rescatada por 
procesos -no de construcción-, sino de demolición de los excesos construidos con el objetivo de salvar una parte de la obra ya construida a fin de hacerla viable. En palabras del curador del pabellón Carlos Quintáns:

Se busca una arquitectura que si bien necesita de su construcción. "UNFINISHED" plantea la demolición como herramienta arquitectónica para intervenir en lo heredado, el esponjamiento de lo construido o la regeneración vegetal entre lo construido. (Quitans. 20।8)

En la historia de la arquitectura, uno de los referentes más significativos de la rápida desaparición de la arquitectura es el Conjunto habitacional Pruitt lgoe en Missouri (197I), proyecto a partir del cual, Charles Jencks (1983) declararía no sólo la desaparición de una arquitectura, sino la de toda una corriente arquitectónica: el Movimiento Moderno [Figura 3].

Todo lo anterior llevó a desarrollar una investigación que abordara el fenómeno de lo efímero en la arquitectura reciente en Colombia, siguiendo una hipótesis principal: el afán por anteponer los resultados a la calidad, y la economía a la duración, ha gestado una noción soterrada de lo efímero en arquitectura, como condición subyacente en las actuales políticas y modos de gestión de los proyectos. A partir de esta hipótesis, este artículo elabora un modelo interpretativo de lo efímero en la arquitectura contemporánea en Colombia a comienzos del siglo XXl, como resultado de tales políticas de gestión, con el objetivo de evidenciar una aproximación otra de la noción de lo efímero en arquitectura.

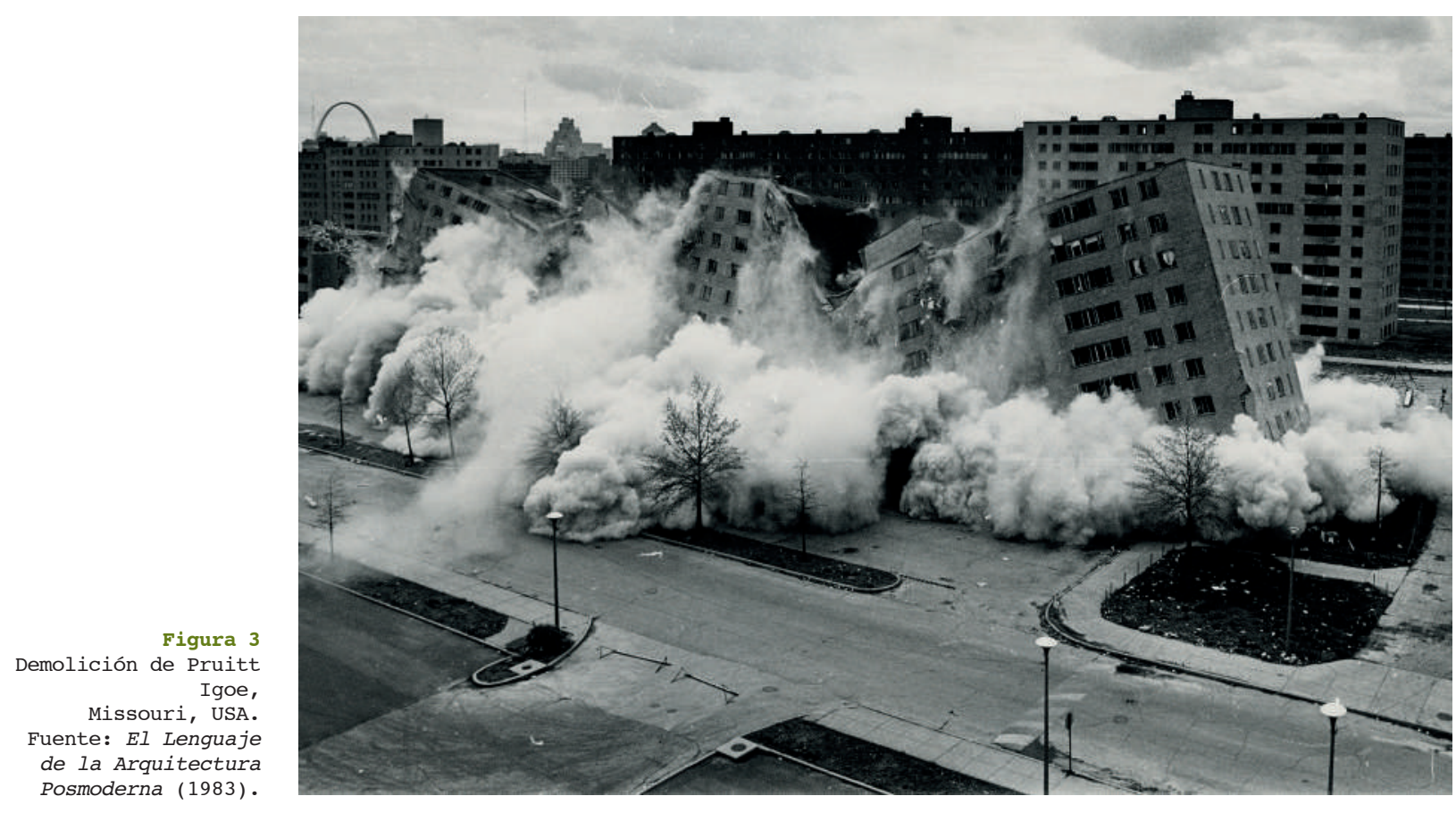




\section{ENFOQUE}

\section{METODOLOGÍA}

FENÓMENOS DE LO EFÍMERO. OTRAS ARQUITECTURAS EFÍMERAS EN COLOMBIA

William García Ramírez.
Uno de los principales problemas de esta investigación es el vacío teórico que se asume, al abordar una noción de lo efímero desde una perspectiva no convencional, pues la mayor parte de la literatura que aborda el tema, supone la entera dominación de lo efímero a una arquitectura que premeditadamente anticipa su desaparición, y en la que: "la sinergia entre las técnicas de arquitectura y la falta de necesidad de crear estructuras perpetuas, constituye la esencia de la arquitectura efímera" (Bayona 2016). Otros autores, sin embargo, han asumido la condición de lo efímero desde el ángulo de la ingeniería forense, una explicación de las causas de fallas estructurales desde una perspectiva patológica, en la que se asocia calidad estructural con seguridad y permanencia de la edificación (Saiz De Cueto, et al. 200 I). La perspectiva teórica aquí abordada implica entonces, el reto de mostrar una faceta otra de lo efímero en arquitectura, como resultado de una tendencia a acelerar los procesos de gestión y/o construcción de edificios, mediante una caracterización de las lógicas conceptuales que envuelven este fenómeno en la actualidad.

Para este efecto, se ha propuesto analizar el fenómeno de lo efímero desde un ángulo, donde la condición de durabilidad de la arquitectura está asociada a su calidad y/o a una política de gestión, y no a su provisionalidad o a la necesidad temporal de ofrecer un albergue, una condición inusitada de lo efímero ocasionada por razones que van desde una inadecuada gestión, un mal diseño arquitectónico y/o estructural, hasta causas macroeconómicas, que configuran una condición donde lo efímero se constituye en condición atípica en la arquitectura reciente en Colombia.

En este contexto, lo efímero se aproxima a una condición de mutabilidad de lo material a lo inmaterial, en el que la temporalidad, la duración de tal mutación, fue el determinante de las escalas de tiempo que caracterizan dos aproximaciones efectuadas en esta investigación a la arquitectura efímera. Estas aproximaciones operan -siguiendo a Fernand Braudel- en periodos que oscilan, desde la larga duración en la desaparición de la obra, hasta la inmediatez de la corta duración o coyuntura en la súbita pérdida de la obra.

La metodología comprendió el desarrollo de 3 fases con el objetivo de comprobar la hipótesis de investigación, una metodología de tipo analítico - descriptivo, toda vez que se trató de la disección de un conjunto de proyectos arquitectónicos, a fin de comprender desde diferentes ángulos y extraer en una síntesis una concepción alternativa de lo efímero en la arquitectura. Tratándose de un balance historiográfico del fenómeno de la arquitectura efímera en Colombia, se recogió una documentación en parte inédita, y se la contrastó en el marco de la historia ya conocida sobre el tema, a la vez que se examinó esta documentación con el fin de transformar el conocimiento inicial de los proyectos en un panorama crítico de la arquitectura en Colombia. 


\section{FASES DE DESARROLLO}

\section{RESULTADOS. \\ UTOPÍAS / DISTOPÍAS DE LO EFÍMERO}

1. Recolección y sistematización a través de fichas de información de proyectos arquitectónicos desaparecidos o, en proceso de desaparición, por razones constructivas, o de políticas de gestión, obras que por su relevancia, hiciesen parte de los proyectos seleccionados en bienales colombianas de arquitectura, y/o objeto de estudio en tesis y artículos de investigación.

2. Análisis historiográfico que permita detentar causas y consecuencias de estos proyectos fallidos, con el fin de agruparlos bajo categorías analíticas en común, con las cuales se pueda someter a comprobación la hipótesis central de la investigación.

3. Construcción de una línea de tiempo que permita comprender un panorama crítico de la arquitectura efímera en Colombia, a la luz de la hipótesis de investigación planteada.

El análisis de las planimetrías del conjunto de obras analizadas reveló como factor común, la generosidad en los espacios y especificaciones de las obras, en tanto se trataba de proyectos orientados, en su mayoría, a grupos sociales de ingresos económicos medios y altos. Estas condiciones de privilegio, proyectadas en los planos y renders de las obras, dan cuenta de una serie de lugares ideales de visión utópica, los cuales posteriormente derivaron en todo lo contrario, espacios indeseables e imposibles de habitar, ya fuese por su repentina desaparición o por el abandono al que fueron sometidos, convirtiéndolos en espacios ya no utópicos sino distópicos, como síntesis de antivalores del hábitat construido. Esta situación paradójica llevó a considerar las nociones de utopía / distopía como esquema teórico inicial sobre el cual se situaron y contextualizaron los hallazgos investigativos.

De esta manera se conformó un inventario con el conjunto de obras analizadas, a fin de entender las distintas visiones atípicas de lo efímero en la arquitectura, cuya clasificación se estructuró tanto por las condiciones físicas de la obra (utopía I distopía), como a partir de las condiciones de tiempo expresadas en la velocidad de desaparición de estas obras (rápida / lenta). De esta manera, arquitecturas desaparecieron parcial o completamente de manera rápida e inintencionada, conformaron una primera categoría denominada (UTOPÍAS DE LO EFÍMERO), mientras que un segundo grupo de arquitecturas que desaparecieron parcial o completamente, pero de manera lenta e intencionada, constituyeron una segunda categoría de análisis denominada (DISTOPÍAS DE LO EFÍMERO). 


\section{UTOPÍAS DE LO EFÍMERO: CORTA DURACIÓN / RÁPIDA DESAPARICIÓN}

El accidente es un milagro al revés- Es un revelador último que nos permite evaluar los estragos del progreso... El accidente es, pues, la cara oculta del progreso técnico y científico.

Paul Virilio
Virilio (1997), advierte sobre el peligro de una sociedad esclava del progreso, como utopía contemporánea, que, por efecto de la excesiva velocidad de los procesos, rápidamente puede convertirse en una distopía del infortunio y la desgracia. Esta condición de fugacidad, de permanente cambio, propia de la vida de finales del siglo $X X$ y comienzos del siglo XXl, ha puesto en cuestión los modos de consumo y hábitat de las personas $y$, por ende, ha puesto en cuestión a la arquitectura como disciplina del firmitas, de lo estable y permanente y duradero.

Las causas del fenómeno Utopías de lo efímero no se remiten exclusivamente a errores constructivos, sino a fallos operativos y de conveniencia política. En palabras de Adrian Forty:

\footnotetext{
El escándalo de casi todos los fallos de construcción es que lo previsible fue ignorado. Las investigaciones post-accidente tienden a concentrarse en las causas técnicas del fallo, pero raramente son el corazón del problema. Lo que deberían estar abordando son los mecanismos que llevaron a las personas a dejar de lado los conocimientos que ya tenían - y esos mecanismos van desde la conveniencia política hasta una predisposición psicológica a no creer en los riesgos. (Forty, 2019) Traducción:William García.
}

Conveniencias políticas y económicas, en cuyo trasfondo se esconde el urgente afán de progreso, y la necesidad de eficiencia tienden a subyugar el mercado de la construcción. De esta manera, la noción de "progreso" se ha convertido de manera equívoca en sinónimo de "eficiencia". De allí que, en algunas empresas, una gran velocidad de diseño y construcción se constituya en uno de sus principales objetivos, lo que en el mundo de las economías justifica la excesiva simplificación de los procesos y en casos extremos, el descuido de aspectos elementales de diseño y/o construcción, todo en aras de las exigencias de eficiencia y el ahorro de recursos. Así, la arquitectura del "más por menos", y del "low cost" lleva a sus promotores a extremar en la simplificación de los procesos, en el que todo vestigio de diseño que implique mayores costos es rápidamente eliminado; sin embargo, una vez construidas estas arquitecturas, rápidamente se vislumbran los defectos y deterioros de una arquitectura, fruto de la velocidad y el ahorro. Es la arquitectura de la avaricia y la codicia, del fin por encima de los medios, una arquitectura cuya corta duración y rápida desaparición, ha ocasionado graves consecuencias en nuestro país.

El 12 de octubre de 2016 a las 8:20 p.m. colapsa en la ciudad de Medellín, la etapa 6 del complejo Space, un edificio de 23 pisos y 4 sótanos construido apenas hacía 8 meses, debido a una insuficiente capacidad estructural del edificio (Yamin, et al., 2018). Se trataba de un conjunto de apartamentos provisto de grandes áreas, acabados de lujo, generosos espacios comunes, ubicado en uno de los sectores más privilegiados de la ciudad [Figura 4]. Así, las utopías de lo efímero represen- 


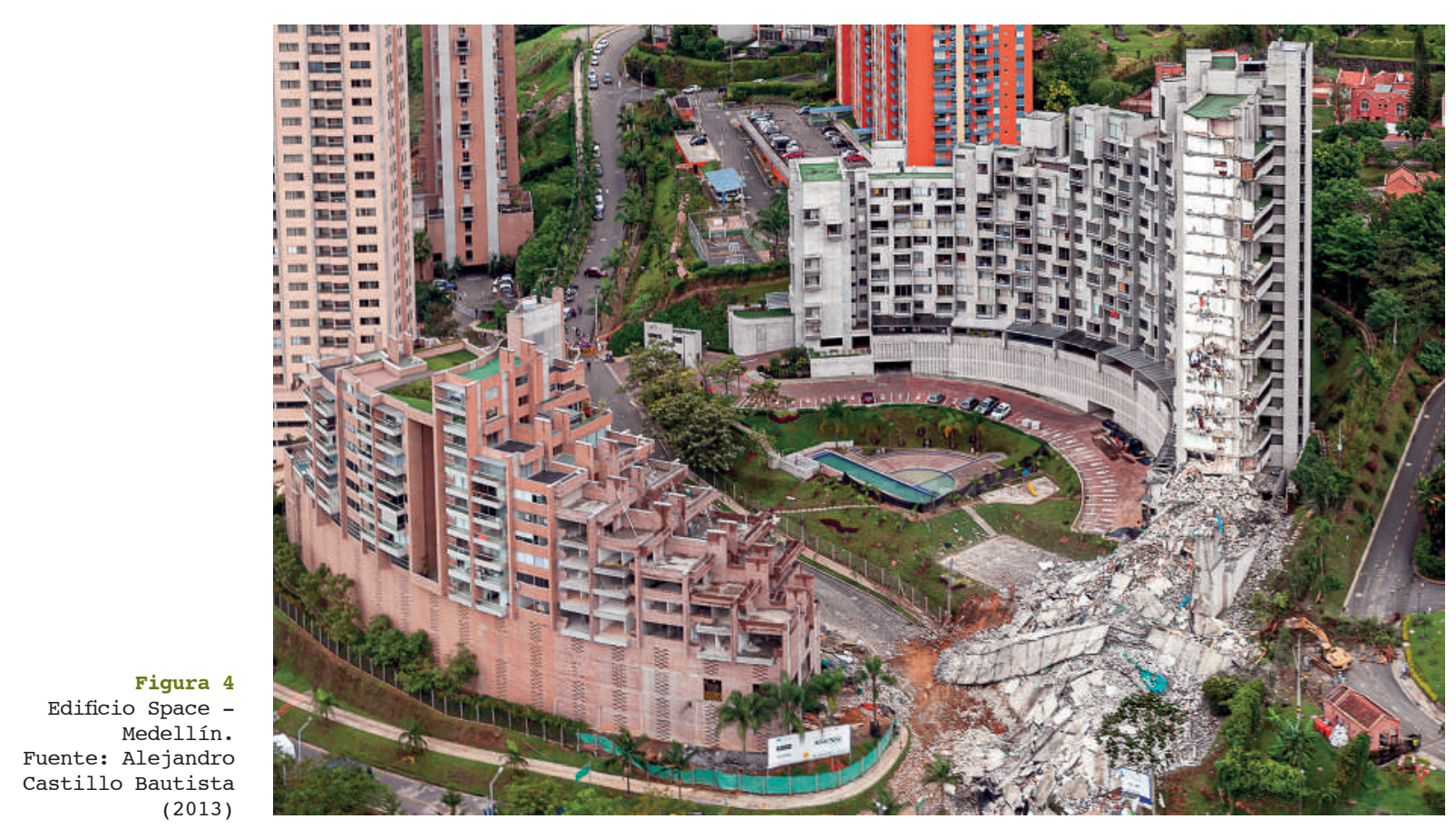

(2013)

tan por lo tanto, un hábitat ideal de arquitectura, que de repente desaparece por fallos constructivos y/o de diseño, convirtiendo en ruinas lo que otrora fue un espacio ideal, un fenómeno inusitado en el que el diseño arquitectónico y/o constructivo de estas arquitecturas es la que determina la medida temporal de su existencia; de manera que lo que estaba previsto para durar muchos años, se convierte en perecedero por la coyuntura de una situación, por la imprevisión de una realidad. Lo efímero, entonces, se encuentra atado en estos casos a una condición de consecuencia repentina y no de causa planificada, como ocurre con la mayoría de las arquitecturas previsiblemente efímeras. En síntesis, las utopías de lo efímero son una construcción de la destrucción.

En un mundo donde el excesivo consumo de materiales, energías y recursos va en contravía de los principios más elementales de la sostenibilidad ambiental (Shen et al. 2005, según Enshassi 2014), las arquitecturas efímeras, con un reducido ciclo de vida de sus materiales, desafían tales principios pues su pérdida y eventual reconstrucción implican un esfuerzo significativamente mayor, que si se hubiesen construido de manera adecuada desde la primera vez.

Sin duda se trata de un fenómeno característico de comienzos del siglo XXl, dado que no se detectaron registros en el siglo pasado de casos de arquitecturas significativas que hayan fallado o que hayan tenido que ser demolidas al poco tiempo de ser construidas, por el contrario, la excelencia y el buen oficio que suelen caracterizar la arquitectura en Colombia, limitan la demolición de edificios para optar por otras soluciones. 


\section{BIBLIOTECA ESPAÑA}

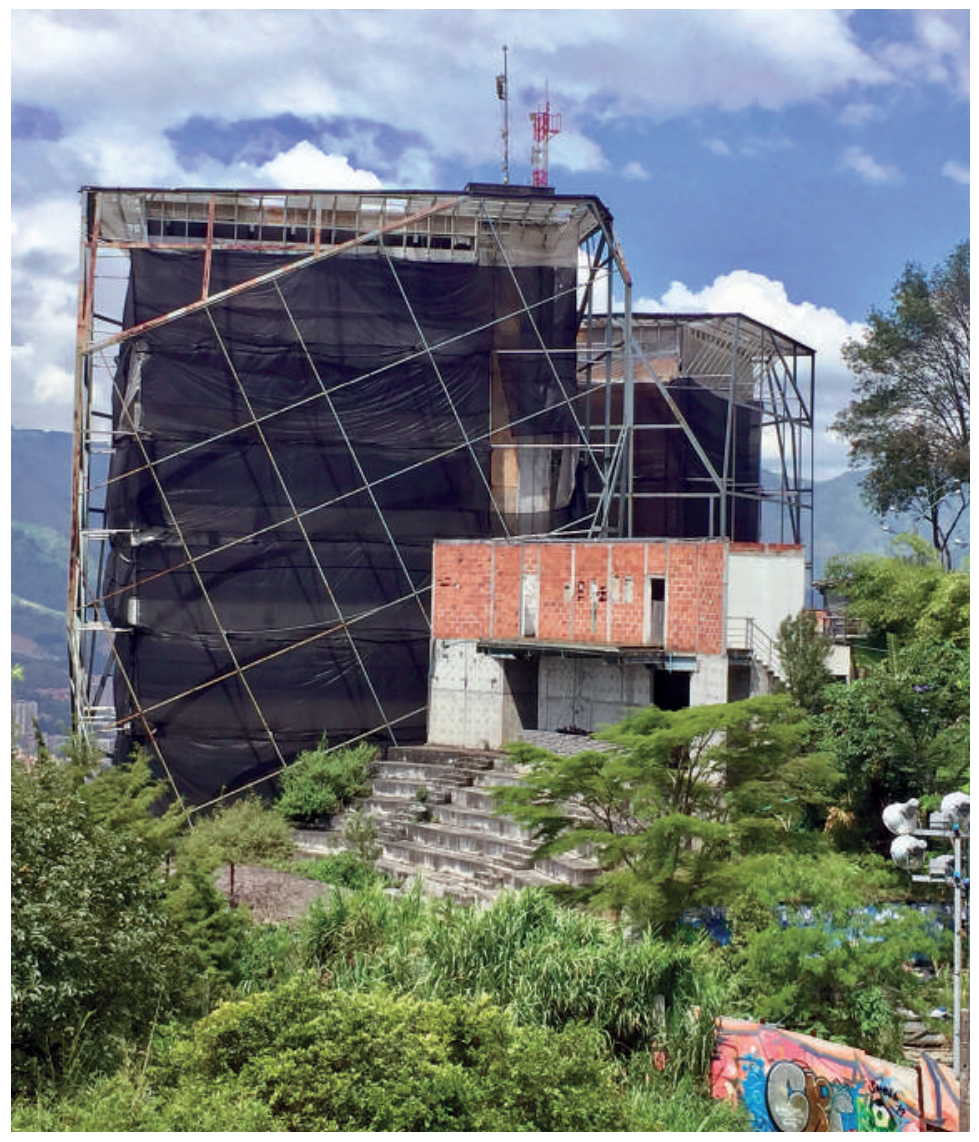

El Parque Biblioteca España es uno de los proyectos construidos en el país que con mayor precisión encarna las lógicas de una Utopía de lo efímero. Una muy rápida ejecución, sumada a una serie de improvisaciones durante su construcción, condujo a la rápida conversión de un espacio premiado internacionalmente, en una ruina inhabitable, abandonada hace más de 5 años [Figura 5].

El Parque Biblioteca España hizo parte del conjunto de cinco Parques Biblioteca construidos en la ciudad de Medellín, que -salvo el caso en mención- se mantienen en funcionamiento hasta el día de hoy. Inaugurado por los reyes de España en 2007, la biblioteca empezó a sufrir filtraciones de agua por sus fachadas poco tiempo después de su apertura, posteriormente fue el recubrimiento de las fachadas el que sufrió desperfectos que provocaron su progresivo desprendimiento hasta hacer imposible el uso de los espacios, lo que llevó a su cierre en 2013, recientemente, un estudio de vulnerabilidad determinó que la estructura tampoco cumple con las normas de sismo resistencia. A pesar de los estudios realizados por diferentes instituciones, tendientes a buscar soluciones que hagan viable nuevamente el proyecto, lo cierto
Figura 5

Biblioteca España, Medellín. Fuente: William García R (2019). 
es que hasta el día de hoy ( 13 de enero de 2020) el Parque Biblioteca España está cerrado al público.

El entonces Secretario de Planeación de Medellín, Jorge Pérez Jaramillo, sintetiza en su libro Medellín Urbanismo y Sociedad (2019), la situación de este edificio:

Un edificio escultural, con una localización emblemática, complemento poderoso a través del Proyecto Urbano Integral del primer Metrocable de Santo Domingo (200I-2004), precursor de la intervención en el barrio, ha sido finalmente un desastre para todos, pues sus precarias condiciones materiales y constructivas derivaron en su desalojo, colapso y posterior cierre. El edificio está destinado a ser un símbolo: lo que una vez significó transformación hoy es testimonio de precariedad constructiva y de gestión. (Pérez 2019)

A continuación, se presenta una síntesis de los casos más relevantes en el país que encarnan la noción de Utopía efímera, y que revelan cómo la condición de lo efímero se extiende más allá de arquitecturas previsiblemente temporales:

Tabla 1

Utopías De Lo Efímero nn Colombia. Fuente: Elaboración propia

\begin{tabular}{|c|c|c|c|c|c|c|c|}
\hline & Proyecto & Altura/Dimensión & Año Construcción & Año Evacuación & Año Demolición/Estado & Ciudad \\
\hline \multirow{12}{*}{$\begin{array}{l}\frac{n}{5} \\
\frac{4}{4} \\
\frac{1}{4} \\
\frac{n}{5} \\
\frac{n}{0} \\
0 \\
5\end{array}$} & 1 & Edificio Altos del Lago & 18 pisos & 2016 & 2017 & 2019 & Rio Negro \\
\hline & 2 & Puente Chirajara & 446 m Longitud & 2016 & 2018 & 2018 & Chirajara \\
\hline & 3 & Edificio Portal Bals de Leso II & 6 pisos & 2016 & 2017 & 2018 & Cartagena \\
\hline & 4 & Ciudadela del Saber & 3 pisos & 2015 & 2018 & Abandono & Puerto Lleras \\
\hline & 5 & Edificio Babilonia & 13 pisos & 2015 & 2018 & 2019 & Medellín \\
\hline & 6 & Edificio Altos de la Mota & 26 pisos & 2011 & 2019 & 2019 & Medellín \\
\hline & 7 & Edificio Asensi & 10 pisos - escalonado & 2008 & 2013 & 2018 & Medellín \\
\hline & 8 & Edificio Bernavento & 20 pisos & 2008 & 2013 & Abandono & Medellín \\
\hline & 9 & Biblioteca España & 6 pisos - 3 bloques & 2007 & 2016 & 2018 & Medellín \\
\hline & 10 & Edificio Continental Tower & 19 pisos & 2007 & 2013 & Abandono & Medellín \\
\hline & 11 & Edificio Space & 23 pisos - escalonado & 2006 & 2013 & 2013 & Medellín \\
\hline & 12 & Torre de la Escollera & 50 pisos & 2006 & 2008 & 2008 & Cartagena \\
\hline
\end{tabular}


DISTOPÍAS DE LO EFÍMERO: LARGA DURACIÓN / LENTA DESAPARICIÓN

Figura 6

William García

(2019) Edificio

ICFES. Arq. Aníbal

Moreno.

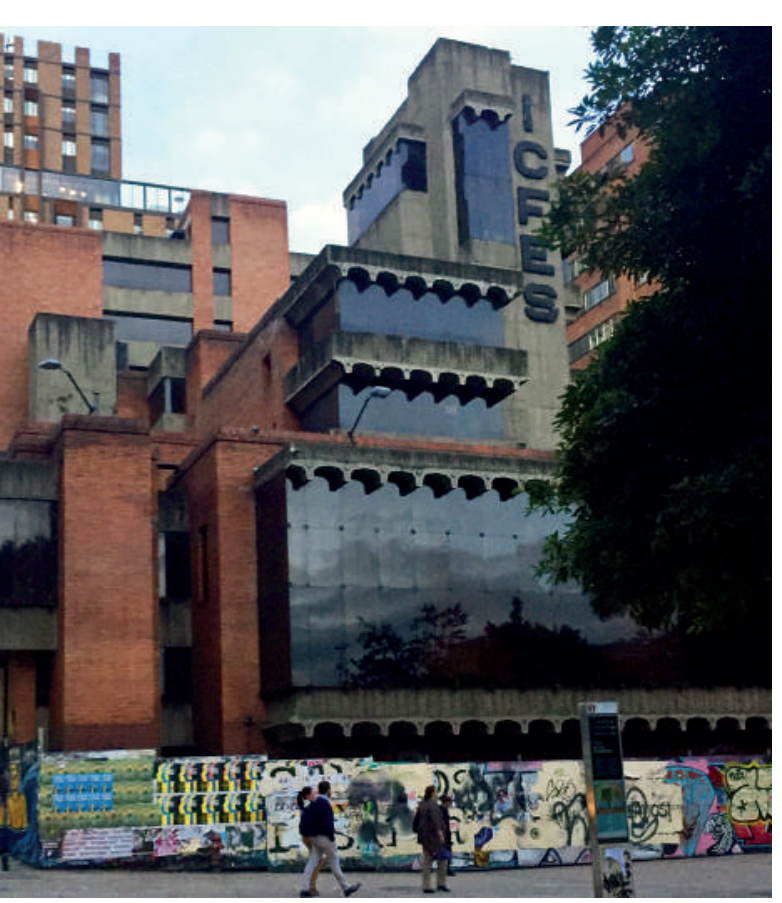

Esta categoría se caracteriza por arquitecturas de significativo diseño que, paradójicamente, han sido desalojadas, o nunca han sido habitadas. Por lo tanto, se trata de arquitecturas sin uso, abandonadas durante largos periodos de tiempo, por lo que el estado de ruina arquitectónica es una de sus características más representativas. La noción de lo efímero se produce, entonces, a partir de la lenta y progresiva desaparición de estas obras, causada por el estado de ruina en que se encuentran. De esta manera, proyectos concebidos como lugares de esparcimiento, cultura o vivienda que, de haber sido finalizados y/o utilizados apropiadamente, hubiesen configurado hábitats ideales, se han convertido en espacios inhabitables, en distopías de lo efímero, arquitecturas que han perdido su razón de ser, para convertirse en no-lugares, espacios sin sentido, en lento tránsito hacia su desaparición.

Una de las principales características de las distopías de lo efímero es su diversidad de tipologías y escalas, se trata de proyectos de amplia índole y envergadura, que comprenden desde centros culturales, colegios, viviendas patrimoniales, hasta edificios estatales, todos ellos víctimas del abandono producido por la falta de presupuesto, incumplimiento en los contratos, cambios en las políticas de infraestructura, o desavenencias entre promotores y arquitectos.

La presencia de estas obras en las ciudades tiende a pasar inadvertida, dada su poca o nula relación con los patrones de acontecimiento cotidianos del contexto que le rodea, así, las distopías de lo efímero se constituyen en espacios bien diseñados y construidos, pero no habitados. [Figura 6]. Lo efímero en este tipo de arquitectura se visibiliza, entonces, en las consecuencias de la transformación que sufren estos espacios en el tiempo, una transformación casi imperceptible en el día a día, que de no ser intervenidas, tienen un fin asegurado: su desaparición [Figura 7].

La condición perecedera en este tipo de arquitectura no tiene que ver, -como en el caso de las Utopías de lo efímero- con un problema de calidad en el diseño, sino con una cuestión de durabilidad de los materiales con los que está construida. Así, son numerosos los casos en Colombia de inmuebles patrimoniales con mucha historia y poco futuro, cuyos propietarios deliberadamente dejan en el abandono, con el fin de lograr una declaratoria de ruina por parte de las autoridades que les permita terminar de demolerlos, y en su lugar construir rentables edificios. Sin embargo, en ocasiones son las mismas autoridades, que haciendo alarde de su poder, invocan la ruina sobre propiedades públicas, este fue el caso del edificio de la Plaza Central de Mercado, un edificio víctima del abandono oficial como medio para causar su desaparición. A este respecto, el Decreto 463 de 1953 emitido con este objetivo expresaba:

Que como medio para provocar una solución en el tiempo, por las consecuencias que acarrearía la permanencia de un estado indefinido de agotamiento en la utilidad de los inmuebles destinados a las plazas de mercado, el Acuerdo 54 de 1949 prohibe hacerles ampliaciones y mejoras. (García 2017) 


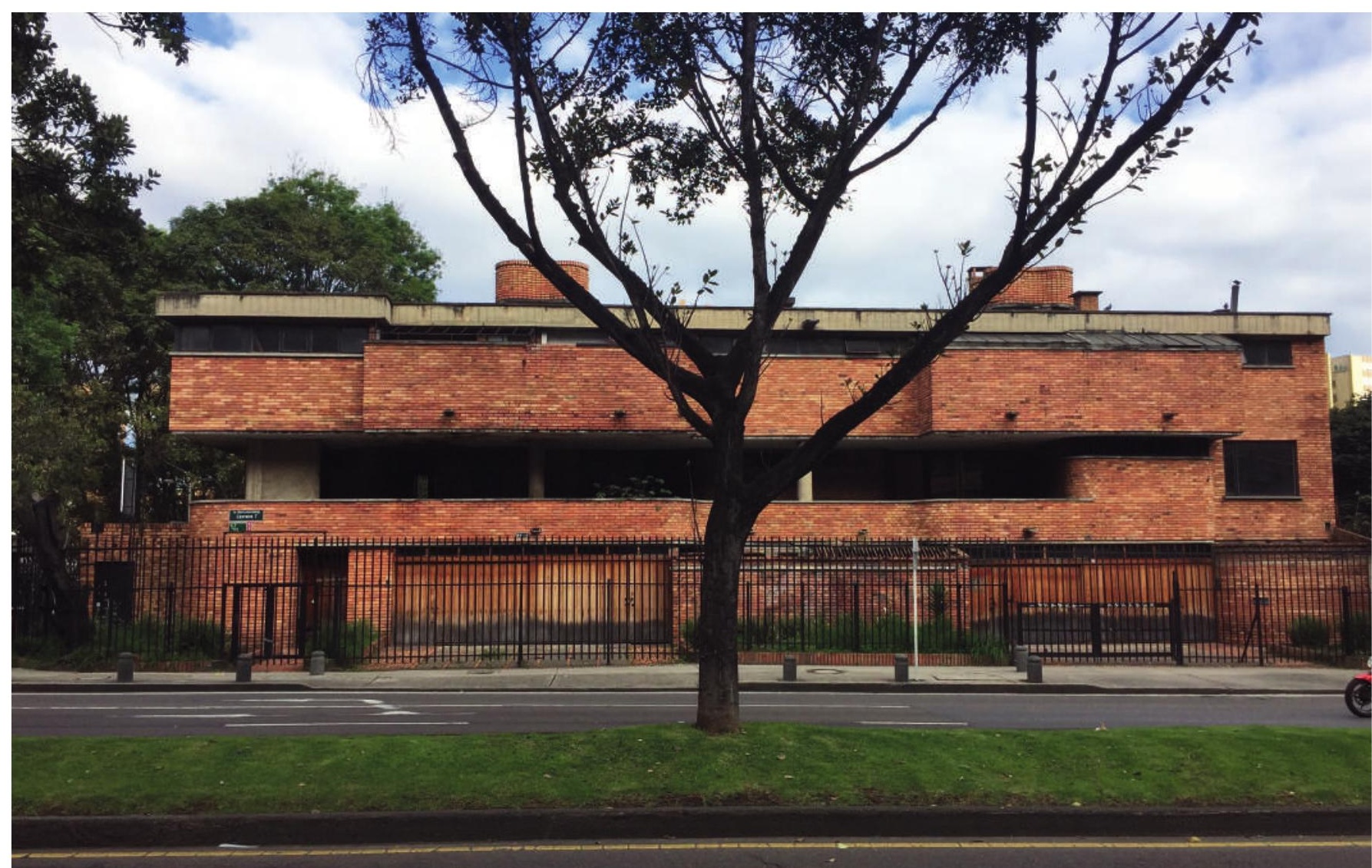

Figura 7

William García

(2019). Edificio

ICFES. Arq. Aníbal

Moreno.

Aunque previstas para ser ocupadas y utilizadas por largos periodos, algunas de estas distopías de lo efímero son arquitecturas que quedaron atrapadas en un limbo entre la construcción y la ocupación efectiva de estos espacios, arquitecturas efímeras en el sentido de lo pasajero, en su acepción de lo transeúnte, de lo que está en permanente estado de tránsito, entre la construcción y la ocupación, entre la construcción y la ruina. En este caso, la condición de lo efímero, en términos de tiempo, tiene que ver con su duración incierta, un lento devenir sin fecha ni término, es el paso constante del tiempo sin que jamás se finalice la construcción. En estos casos, la acción de la intemperie y la inacción de sus dueños son las causas de la lenta desaparición de estos inmuebles. Si de lo efímero solo queda el recuerdo de una experiencia, de las distopías de lo efímero sólo queda el olvido, pues se trata de edificios sin habitantes que las ocupen, ni ciudadanos que las recuerden. Así, lo efímero no solo implica la ausencia de tiempo, sino la ausencia de actividad que valide la existencia de estos espacios. 


\section{CENTRO CULTURAL JORGE ELIECER GAITÁN Arq. Rogelio Salmona}

Fruto de un concurso de arquitectura promovido por el Ministerio de Obras Públicas, ganado en 1979 por el Arq. Rogelio Salmona con la colaboración del Arq. Jorge Venegas, el Centro Cultural Jorge Eliecer Gaitán [Figura 8 y 9] fue uno de los fundadores en el país de una naciente tipología apenas conocida en el medio colombiano: los centros culturales (Téllez 2005). Localizado en el barrio Teusaquillo de la ciudad de Bogotá, esta obra se proyectó con un programa que mezclaba un museo, talleres de capacitación, auditorio, oficinas y la casa donde vivió Jorge Eliecer Gaitán. Su construcción se inició en el año de 1988, nueve años después de efectuado el concurso, con unos planos que distaban significativamente de los presentados entonces, las obras avanzaron lentamente durante dos años hasta el año de 1990, quedando inconcluso desde entonces y hasta la actualidad (2019).

En 2005, el gobierno nacional hace entrega de las ahora ruinas del Centro Jorge Eliecer Gaitán a la Universidad Nacional de Colombia, desde entonces, la universidad se ha encargado de rehabilitar varias casas patrimoniales del conjunto incluida la casa de Jorge Eliecer Gaitán. Así, este centro cultural, abandonado hace ya casi 3 décadas, ha adquirido en sus espacios la pátina del tiempo, un paisaje de la ruina que para muchos resulta elocuente y bello, una atmósfera espacial imprevista, pero no por ello digna de contemplación. [...] un "nuevo paisaje que no es propiamente humano ni propiamente natural, sino de acción conjunta, un paisaje onírico, escultórico y arqueológico, entendiendo que los fragmentos que lo componen son capaces de interpretar una creación humana/natural que otorga belleza a lo elemental y a su vez es posible reconstruir una historia incompleta, develando un sentido de existencia humana" (Gilles et al., 2018). Así lo consideraba el mismo Rogelio Salmona:

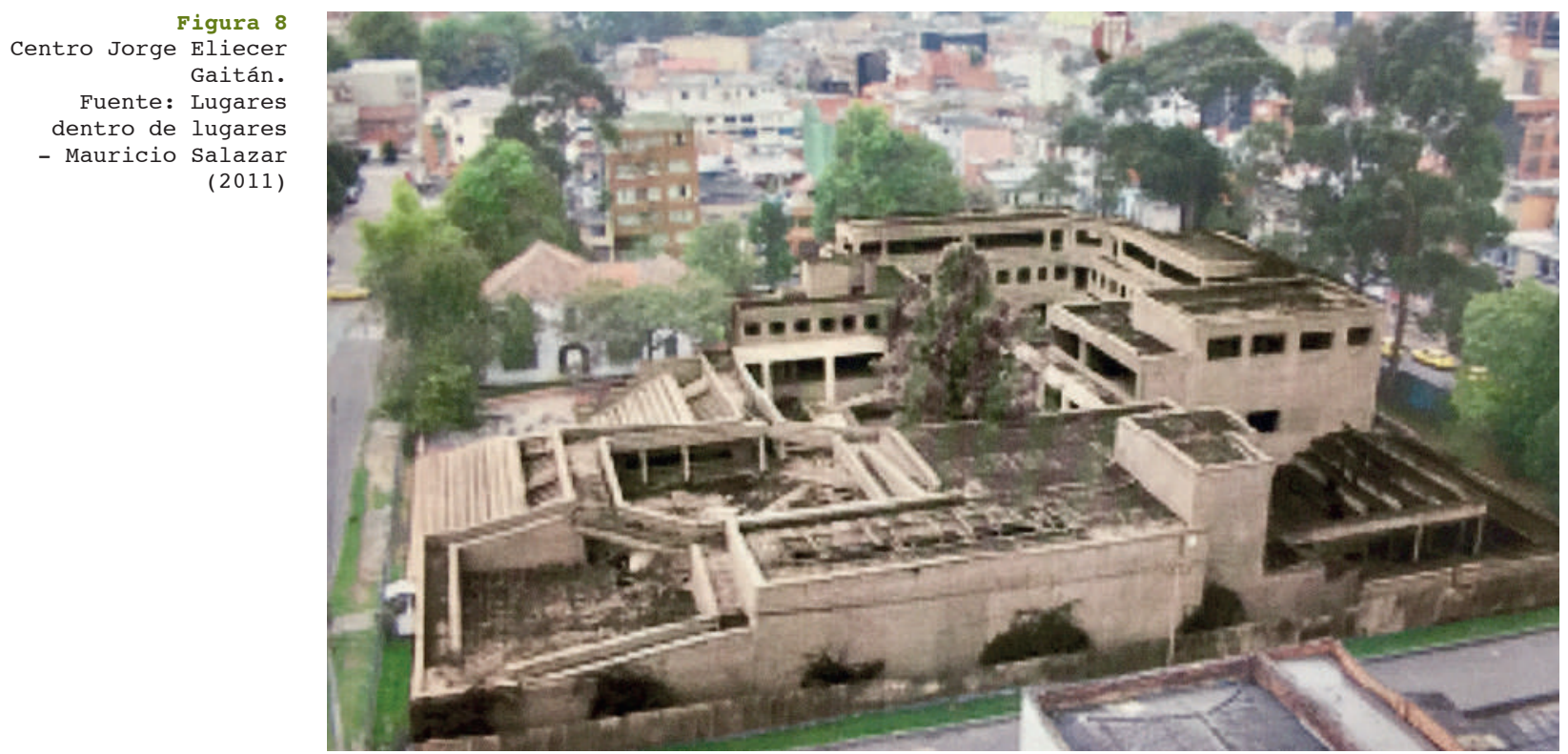




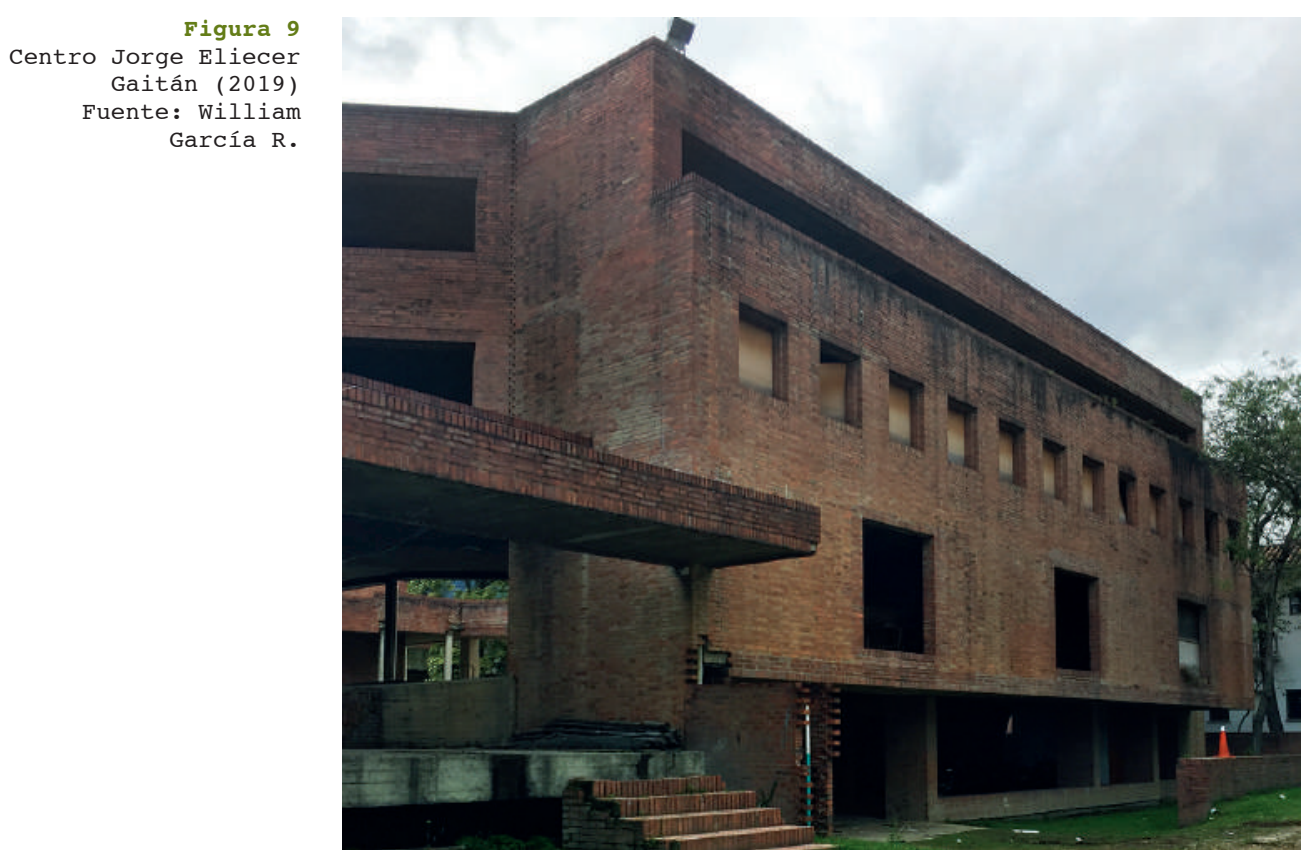

El siguiente cuadro sintetiza algunos de los principales casos en el país, donde lo efímero apunta a la lenta desaparición de inmuebles cuyo gran valor patrimonial, -reconocido por los organismos estatales- no ha logrado, sin embargo, detener el proceso de ruina y lenta desaparición en el que actualmente se encuentran. Así, arquitecturas reconocidas por su gran valor y calidad se ven sometidas a su desaparición, no por cuestiones de calidad -como en el caso de las utopías efímeras- sino a pesar de su gran calidad.

Tabla 2

Distopías de lo efímero en Colombia.

Fuente: Elaboración propia.

\begin{tabular}{|c|c|c|c|c|c|}
\hline & Proyecto & Arquitecto & Año de Construcción & Estado Actual 2019 & Ciudad \\
\hline \multirow{10}{*}{ 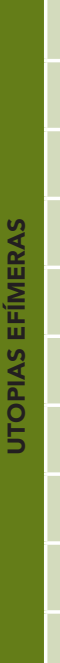 } & Centro Cultural Jorge E. Gaitán & Rogelio Salmona y Jorge Venegas & $1988-1990$ & Abandono & Bogotá \\
\hline & Edificio ICFES & Anibal Moreno & $1968-1972$ & Abandono & Bogotá \\
\hline & Centro Infantil Sesquilé & Fernando Martínez & 1960 & Abandono & Sequilé \\
\hline & Casa Blanca M. de Ponce & Fernando Martínez & 1955 & Abandono & Bogotá \\
\hline & Edificio ESSO & Lathrop Douglas \& Martínez Cardenas & 1957 & Abandono & Bogotá \\
\hline & Teatro Murillo & Manuel Carrera Machado & 1939 & Abandono & Barranquilla \\
\hline & Teatro San Jorge & Alberto Manrique Martin & $1936-1938$ & Abandono & Bogotá \\
\hline & Bernavento & Franz Tutzer (Alemania) & $1928-1934$ & Abandono & Bucaramenga \\
\hline & Edificio Admon Hospital San Juan de Dios & Ramón J. Cardona y Pablo De la Cruz & $1914-1926$ & Abandono & Bogotá \\
\hline & Edificio Continental Tower & Pablo De la Cruz & 1921 & Abandono & Bogotá \\
\hline
\end{tabular}




\section{DISCUSIÓN}

Toda arquitectura una vez construida empieza un largo pero inexorable camino hacia su desaparición. Las causas son de distinta índole, sin embargo, el lapso que acontece entre su construcción y su destrucción ha venido acelerándose y acortándose de tal manera, que en el extremo de lo absurdo, algunas de estas arquitecturas acaban desapareciendo sin siquiera haber sido habitadas.

Los casos del Centro Cultural Jorge Eliecer Gaitán y la Biblioteca España constituyen dos extremos del fenómeno lo Efímero en Colombia y sitúan dos razones principales por las cuales una arquitectura puede convertirse de manera imprevista en una utopía, o, en una distopía de lo efímero.

Mientras que el Centro Jorge Eliecer Gaitán quedó inconcluso y en curso de ruina, por desavenencias con el promotor, la Biblioteca España se convirtió en ruina por descuidos de orden constructivo. Estas dos razones, produjeron dos condiciones de lo efímero en arquitectura que ilustran bien las consecuencias de acelerar (o retardar) excesivamente, el paso del tiempo en una obra.

El rápido deterioro de la Biblioteca España apunta a un sentido de lo efímero, entendido como antítesis del progreso, es decir, la privación de lo que se poseía y ya no se tiene, en este caso, la privación de una infraestructura que forzosamente tuvo que ser abandonada. En el caso del Centro Jorge Eliecer Gaitán, fueron los inconvenientes presupuestales del promotor de la obra los que generaron un sentido otro de lo efímero, y en particular de la ruina, como conjunto de evocadores escenarios de lo que "podría haber sido y nunca fue", escenarios en los que se revela una belleza intrínseca y nostálgica de una arquitectura que día a día, desde hace más de 30 años, se consume en el tiempo. Sin duda, ambos proyectos encarnan la pérdida de cuantiosos recursos y esfuerzos, pues en todos los casos, el costo de lo efímero se traduce en pérdida material del proyecto, más aun, cuando esta pérdida no estaba proyectada ni imaginada como sucede en los casos analizados en esta investigación.

Por otra parte, se trata de dos proyectos altamente reconocidos en Colombia por distintas razones. Mientras que el Centro Gaitán se constituyó sin proponérselo en un hito de la arquitectura, reconocido por las autoridades patrimoniales como bien de interés cultural, la Biblioteca España nació con la pretensión de ser un hito, y lo fue: premiado internacionalmente y hoy convertido en ruina, esta biblioteca encarna el fenómeno de los hitos efímeros, creaciones construidas al ritmo de la urgencia, con el afán de lograr lo que en el pasado solo algunas arquitecturas lograban con el paso del tiempo.

Ante un panorama en el que la baja calidad de las nuevas arquitecturas es una característica asociada a lo efímero, resulta comprensible el auge que tiene en la actualidad, la noción de Retrotopía (Bauman, 2017), nostalgia de un pasado percibido como mejor alternativa de vida futura, que desplaza las utopías de cualquier tipo, en tanto promesa de un mundo mejor. 


\section{BIBLIOGRAFÍA}

AL-BADRI, D. (2003) Kansai Airport: A Beautiful Loser. En: Japan Inc Issue 47

BAUMAN, Z. Retrotopía. Serie Paidós - Estado y Sociedad. Bogotá. Planeta. 2017

BAYONA, X. Arquitectura Efímera. En: Arquitectura efímera 100 proyectos. Alex Vidella Ed. Barcelona. Promopress. 2016.

CARNICERO, I. \& QUITANS, C. Unfinished. El pabellón español en la XV Bienal de Arquitectura de Venecia. Madrid. Knauf. 2018.

GARCíA, W. Plaza central de mercado. Las variaciones de un paradigma 18491953. Bogotá. Pontificia Universidad Javeriana. Universidad Nacional de Colombia. 2017.

ENSHASSI, A. et al. Evaluación de los impactos medioambientales de los proyectos de construcción. En: Revista ingeniería de construcción. 2014, vol.29 No. 3.

FORTY, A. Structural failure: accidents waiting to happen. The Architectural review, 2019, London No 1458

GILLES, C. et al, Arquitectura en silencio, el valor de la ruina industrial. En Universum. 2018, vol 33 No 1. Universidad de Talca.

JENCKS, Ch. El lenguaje de la arquitectura posmoderna. Madrid. Gustavo Gili. 1981.

MADARIAGA, L. Estudio de caso desplome edificio portales de Blas de Lezo II. Universidad Católica de Manizales. Facultad de Ingeniería y Arquitectura. Especialización en Prevención, Atención y Reducción de Desastres. 2019.

MICHAUD, Y. El arte en estado gaseoso. México. Fondo de Cultura Económica. 2007.

NICOLINI, A. (2018) La Ciudad Universitaria de Tucumán: un sueño inconcluso (1947-1952). En: Ciudades universitarias. Un proyecto moderno en América Latina. Bogotá. Universidad Nacional de Colombia

PÉREZ, J. Medellín. Urbanismo y sociedad. Madrid. Turner Noema. 2019.

PUJOL, S. et al. Investigation of the Collapse of the Chirajara Bridge: A summary of a study conducted by members of $\mathrm{ACl}$ Committee 133, Disaster Reconnaissance. En: Concrete International; Jun2019, Vol. 41 Issue 6, p29-37, 9p

SÁINZ DE CUETO, F. et al. La ingeniería forense y su relación con la seguridad y calidad estructural. En: Ingeniería Civil. Madrid: Centro de Estudios y Experimentación de Obras públicas N.o 124 (Pág 53)

SALAZAR, M. Lugares dentro de lugares el rito de la memoria en la composición arquitectónica: Centro Cultural Jorge Eliécer Gaitán, Rogelio Salmona. Bogotá Universidad Nacional de Colombia. 2011.

SALMONA, R. et al. Espacio público y ciudad. En: Premio Latinoamericano de arquitectura Rogelio Salmona. Bogotá. IDPC. 2014.

TAMAYO ORTIZ, H. Estructura de Biblioteca España no cumple norma de sismo resistencia. En: Periódico el Tiempo, 2018. https://www.eltiempo.com/colom$\mathrm{bia} / \mathrm{medellin/estudio-determino-que-biblioteca-espana-de-medellin-tiene-fa-}$ Ilas-en-la-estructura-253146

TÉLLEZ, G. Rogelio Salmona Obra completa 1959/2005. Bogotá. Escala. 2005. VIRILIO, P. Cibermundo, la política de lo peor. Madrid. Teorema. 1997.

YAMIN, L. et al. (2018) Sudden Collapse of the 27-Story Space Building in Medellin, Colombia. En: Journal of performance of constructed facilities. Volume 32 Issue 3 